\title{
Dextrin- and Conducting-Polymer-Containing Biocomposites: Properties and Behavior as Cellular Matrix
}

\author{
Bruno Teixeira-Dias, Luis J. del Valle, Francesc Estrany, João F. Mano, \\ Rui L. Reis, Carlos Alemán*
}

Dedicated to Prof. Ramon Oliver on the occasion of his retirement

Both $\alpha$-cyclodextrin and linear dextrin are used to prepare biocomposites with poly(3,4ethylenedioxythiophene). Materials are prepared electrochemically in aqueous solution. Comparison with the pure polymer indicates that the electroactivity and electrostability decrease with the incorporation of the dextrins while the electrical conductivity is retained. The different properties of the two biocomposites suggest that the linear dextrin is mainly located at the surface, whereas the cyclodextrin is homogeneously distributed in the polymeric matrix. Cell adhesion and proliferation assays indicate that the cellular activity is significantly higher in the dextrin-containing biocomposites.

B. Teixeira-Dias, Dr. L. J. del Valle, Dr. F. Estrany, Prof. C. Alemán Center for Research in Nano-Engineering, Universitat Politècnica de Catalunya, Campus Sud, Edifici C', C/Pasqual i Vila s/n, Barcelona E-08028, Spain

E-mail: carlos.aleman@upc.edu

B. Teixeira-Dias, Dr. L. J. del Valle, Prof. C. Alemán

Departament d'Enginyeria Química, ETSEIB, Universitat

Politècnica de Catalunya, Avda. Diagonal 647, Barcelona E-08028, Spain

Dr. F. Estrany

Departament d'Enginyeria Química, EUETIB, Universitat

Politècnica de Catalunya, Comte d'Urgell 187, Barcelona E-08036,

Spain

Dr. J. F. Mano, Prof. R. L. Reis

3B's Research Group - Biomaterials, Biodegradables and

Biomimetics, University of Minho, Headquarters of the European Institute of Excellence on Tissue Engineering and Regenerative Medicine, AvePark, 4806-909 Taipas, Guimarãaes, Portugal, and Institute for Biotechnology and Bioengineering, PT Government,

Associated Laboratory, Braga, Portugal

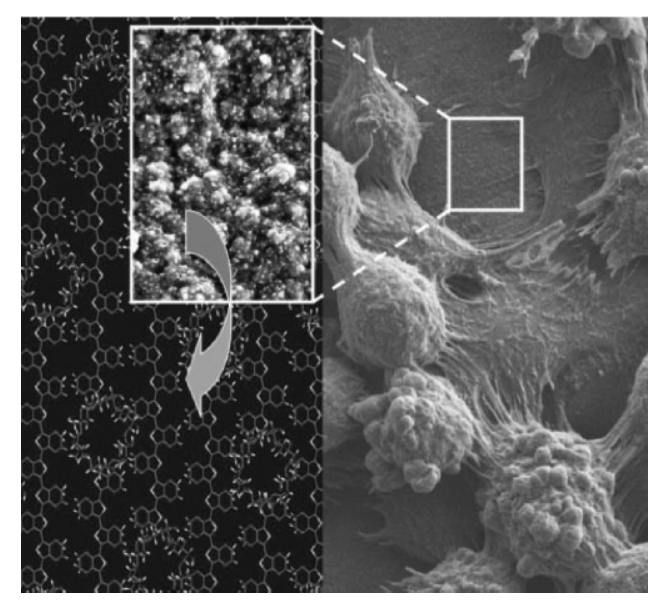

\section{Introduction}

Among conducting polymers (CPs) with $\pi$-conjugated bonds, poly(3,4-ethylenedioxythiophene) (PEDOT), a derivative of polythiophene, has attracted great interest because of its advantageous properties: high electrical conductivity, good electrochemical behavior, thermal and environmental stability, suitable morphologies, and fast doping/undoping mechanism. ${ }^{[1-4]}$ On the other hand, recent studies indicated that PEDOT shows potential applications related with biotechnology and biomedicine. For example, PEDOT is able to interact with specific DNA nucleotide sequences, ${ }^{[5-12]}$ act as a bioactive platform for adhesion and proliferation of cells, ${ }^{[13-17]}$ form biocomposites with collagen, ${ }^{[18]}$ and detect proteins. ${ }^{[19,20]}$

Cyclodextrins (CDs) are toroidally shaped cyclic oligosaccharides with a hydrophobic internal cavity and a 
hydrophilic outer side. They are soluble in water and form stable inclusion complexes with hydrophobic guests that fit tightly inside the CD cavity. The host/guest interaction leads to encapsulation of small particles into the cavity of oligosaccharides without the formation of chemical bonds (i.e., the driving forces for the complexation are noncovalent: van der Waals forces, hydrophobic interactions, etc.) and without changing their chemical structure. ${ }^{[21]}$ Chemical structure, physical properties in solution and solid state, chemical reactivity, electrochemical behavior, formation, and properties of CD polymeric films and biological effects of CDs have been reviewed. ${ }^{[21-25]}$

In the last decade, several composites formed by CPs and CDs have been prepared and characterized. ${ }^{[26-36]}$ Specifically, Lagrost et al. ${ }^{[26,27]}$ prepared composites by electropolymerizing bithiophene and hydroxypropyl- $\beta$-cyclodextrin in aqueous media. Although the resulting composites showed the usual features of poly(bithiophene), the structure of the films appeared to be considerably modified by the presence of $\mathrm{CDs}$ within the material but not grafted onto the polymeric backbone. Shimomura et al. ${ }^{[28]}$ and Yoshida et al ${ }^{[29]}$ studied the insulation effect of an inclusion complex formed by polyaniline in the emeraldine base form and $\beta-C D$ using the oxidation of iodine in solution of $N$ methyl-2-pyrrolidone. Electrochemical methods were also used to prepare composites of polypyrrole and poly(3methylyrrole) with $\alpha$ - and $\beta$-CDs. ${ }^{[30-33]}$ Results evidenced the influence of the $\mathrm{CDs}$ on interchain interactions during the electropolymerization process. ${ }^{[31]}$ In addition, composites made with polypyrrole showed different permeabilities toward a variety of metal ions upon appropriated electrochemical stimuli. ${ }^{[30]}$ Hadziioannou and coworkers described the synthesis and visualization of insulated semiconducting polymers based on polythiophene and polyfluorene, with a high coverage of $\beta$-CDs as insulating sheath. ${ }^{[34]}$ Regarding PEDOT, the only reported composites were recently obtained by electropolymerizing 3,4-ethylendioxythiophene monomer and hydroxypropyl- $\beta-\mathrm{CD}$ in aqueous solution. ${ }^{[35,36]}$ The resulting materials effectively catalyzed the oxidation of sulfur oxoanions and nitrite by reducing their overoxidation potential.

On the other hand, systems based on linear dextrins (LDs) have been found to promote the cellular growth. ${ }^{[37-40]}$ This bioreactive response added to the intrinsic characteristics of PEDOT as conducting bioactive platform ${ }^{[14,16]}$ (i.e., substrate electro-compatible with cellular-monolayers that behaves as a cellular matrix) suggest that the combination of the two materials may result in new composites with important biomedical and biotechnological applications. Specifically, composites formed by PEDOT and dextrins are very promising candidates to act as efficient substrates for the adhesion and growing of eukaryotic cells. In spite of this, some important characteristics of these composites (e.g., the structure and morphology) remain unknown and, in addition, their applicability as cell substrate has not been explored yet.

It is well known that, among the different macromolecules that participate in the cell-material recognition process, glycoproteins play a very relevant role. Thus, carbohydrate domains of glycoproteins are key elements for the recognition of cell/cell and material/cell interactions. Glucose, which is the most abundant carbohydrate in the extracellular matrix, is the building block of dextrins. This work is focused on the preparation and characterization of bioactive PEDOT-containing composites. In order to facilitate the recognition between PEDOT and cells, such CP has been combined with $\mathrm{CD}$ and LD. The utility of the resulting materials, hereafter denoted $\mathrm{P}(\mathrm{EDOT}-\mathrm{CD})$ and $\mathrm{P}(\mathrm{EDOT}-\mathrm{LD})$, respectively, as bioactive platforms has been investigated through cellular adhesion and proliferation assays. The properties of these biomaterials, which were produced by anodic polymerization in aqueous solution, have been characterized in terms of electrochemical and electrical behavior, morphology and structure, and hydrophobicity of the surface. In order to determine the role played by the dextrins on each of these properties, the two biocomposites have been systematically compared with PEDOT. The concentration of dextrins in the biocomposites has been determined and, in addition, their rate of release has been investigated considering different conditions.

\section{Experimental Section}

\subsection{Materials}

3,4-Ethylendioxythiophene (EDOT), $\alpha$-CD (cyclohexaamylose), LD $\left[\left(\mathrm{C}_{6} \mathrm{H}_{12} \mathrm{O}_{6}\right)_{x}\right.$ from potato starch] were purchased from Aldrich. Anhydrous $\mathrm{LiClO}_{4}$, analytical reagent grade, from Aldrich was stored in an oven at $80^{\circ} \mathrm{C}$ before use in the electrochemical trials.

\subsection{Synthesis}

PEDOT, $\mathrm{P}$ (EDOT-CD), and $\mathrm{P}(\mathrm{EDOT}-\mathrm{LD})$ were prepared by chronoamperometry (CA) under a constant potential of $1.10 \mathrm{~V}$ using a polymerization time $\theta=300 \mathrm{~s}$. Both anodic polymerizations and electrochemical experiments were conducted in a three-electrode two-compartment cell under nitrogen atmosphere $(99.995 \%$ in purity) at $25^{\circ} \mathrm{C}$. A VersaStat II (Princenton Applied Research) potenciostat/galvanostat connected to a computer controlled through a Power Suite Princenton Applied Research program was used in all cases. For the preparation of PEDOT, the anodic compartment was filled with $50 \mathrm{~mL}$ of a $0.01 \mathrm{M}$ EDOT solution in ultrapure Millio water containing $0.1 \mathrm{M} \mathrm{LiClO}_{4}$ as supporting electrolyte, while the cathodic compartment was filled with $10 \mathrm{~mL}$ of the same electrolyte solution. For the synthesis of $\mathrm{P}$ (EDOT-CD) and $\mathrm{P}$ (EDOT-LD) the anodic compartment was filled by adding $10 \mathrm{~mL}$ of millio water solution containing the corresponding dextrin $\left(50 \mathrm{mg} \cdot \mathrm{mL}^{-1}\right)$ to $40 \mathrm{~mL}$ of the above mentioned EDOT/ $\mathrm{LiClO}_{4}$ electrolyte solution. Steel AISI $316 \mathrm{~L}$ sheets of $1 \times 1 \mathrm{~cm}^{2}$ were employed as working and counter electrodes. The reference 
electrode was an $\mathrm{Ag} \mid \mathrm{AgCl}$ electrode containing a $\mathrm{KCl}$ saturated aqueous solution $(E=0.222 \mathrm{~V}$ vs. standard hydrogen electrode at $25^{\circ} \mathrm{C}$ ), which was connected to the working compartment through a salt bridge containing the electrolyte solution.

\subsection{Electrochemical Characterization}

The electrochemical properties of PEDOT, P(EDOT-LD), and P(EDOT$\mathrm{CD}$ ) films were studied by cyclic voltammetry (CV). The ability to store charge (electroactivity) and electrochemical stability upon consecutive oxidation-reduction cycles (electrostability) were determined using an ultrapure Millio water solution with $0.1 \mathrm{M}$ $\mathrm{LiClO}_{4}$. The initial and final potentials were $-0.50 \mathrm{~V}$, and the reversal potential was $1.40 \mathrm{~V}$. The electroactivity increases with the similarity between the anodic and cathodic areas of the first control voltammogram, whereas the electrostability decreases with the oxidation and reduction areas of consecutive control voltammograms. Accordingly, electroactivity and electrostability were determined through direct measure of the anodic and cathodic areas in the control voltammograms using the Power Suite Princenton Applied Research software. A scan rate of $100 \mathrm{mV} \cdot \mathrm{s}^{-1}$ was used in all cases.

\subsection{Electrical Properties}

The electrical conductivity $(\sigma)$ was measured on films synthesized on steel AISI $316 \mathrm{~L}$ sheets of $2 \times 2 \mathrm{~cm}^{2}$ area using the sheet resistance method, as was previously described. ${ }^{[41]}$

\subsection{Electrochemical Impedance Spectroscopy (EIS)}

EIS studies were carried using three-electrode two-compartment cell with an Autolab 302N potentiostat/galvanostat and the FRA software program. The cell was filled with $50 \mathrm{~mL}$ of ultrapure Millio water solution containing $0.1 \mathrm{M}$ of $\mathrm{LiClO}_{4}$ and all the measurements were performed at room temperature. Coated and uncoated steel AISI $316 \mathrm{~L}$ sheets of $1 \times 1 \mathrm{~cm}^{2}$ were employed as working and counter electrodes, respectively. EIS measurements were carried out in the $0.05-20 \mathrm{~Hz}$ frequency range and sinusoidal voltage amplitude of $\pm 0.05 \mathrm{~V}$ for 70 frequencies. EIS data were plotted in terms of real and imaginary parts of the impedance $\left(Z^{\prime}\right.$ and $-Z^{\prime \prime}$ respectively).

\subsection{Morphology}

Atomic force microscopy (AFM) images were obtained with a Molecular Imaging PicoSPM using a NanoScope IV controller in ambient conditions. The average root mean square (RMS) roughness $(r)$ was determined using the statistical application of the Nanoscope software, which calculates the average considering all the values recorded in the topographic image with exception of the maximum and the minimum. Nanometric measurements were conducted under ambient conditions at $\approx 50 \%$ relative humidity and $20-22{ }^{\circ} \mathrm{C}$. The system was placed on an active vibration isolation table for minimum acoustic disturbance ( 20 series, TMC, Peabody, MA, USA).
Scanning electron microscopy (SEM) studies were carried out using a Focused Ion Beam Zeiss Neon 40 scanning electron microscope equipped with an energy dispersive X-ray (EDX) spectroscopy system and operating at 3.00 and $10.00 \mathrm{kV}$ (micrographs and EDX analyses, respectively).

\subsection{Contact Angle Measurements}

Contact angles were obtained using the water drop method. Images of water drops $(3 \mu \mathrm{L})$ in the surface of the films were recorded with a contact angle meter (Dataphysics, Contact Angle System OCA15 +) after stabilization $(30 \mathrm{~s})$. The images of the drop shapes were analyzed and the contact angle measures were carried out with the SCA20 software. Measurements were performed four times for each material.

\subsection{Quantification of the Concentration of Dextrins in Composites}

$\mathrm{P}(\mathrm{EDOT}-\mathrm{LD})$ and $\mathrm{P}(\mathrm{EDOT}-\mathrm{CD})$ films were removed from the steel working electrodes using a scraper. The resulting material was transformed into a powder using an Agatha mortar prior to the extraction of the dextrins. Powder of each composite $(6 \mathrm{mg})$ was placed in a glass tube, $5 \mathrm{~mL}$ of sulfuric acid $(12.5 \mathrm{M})$ being added to extract the dextrins. Centrifugation of the tubes was performed after $24 \mathrm{~h}$ to clarify the extracts, and the insoluble material, which forms a pellet, was discarded. The quantification of $\mathrm{LD}$ and $\mathrm{CD}$ was determined using a phenol/sulfuric acid procedure reported by Dubois et al., ${ }^{[42]}$ which consists of the following three steps: (i) $0.5 \mathrm{~mL}$ of extract was mixed with $0.5 \mathrm{~mL}$ of phenol (5\%); (ii) $2 \mathrm{~mL}$ of concentrated sulfuric acid $(\approx 18 \mathrm{M})$ was slowly (10 min) added to the tube, the mixture being agitated at the end; and (iii) the absorbance at $490 \mathrm{~nm}\left(A_{490}\right)$ was measured after rest $30 \mathrm{~min}$. The control blank was prepared with the solution of extraction. Furthermore, PEDOT was extracted as control because of the weak color reaction produced by the aromatic rings. The $A_{490}$ was converted into $L D$ and $C D$ concentration using the respective calibration curves.

The same procedure was used to quantify the concentration of released dextrin in the corresponding release assays (see below). In this case, the concentrations of $L D$ and $C D$ contained in the composites as prepared were used as references.

\subsection{Release Experiments}

Controlled release experiments were performed using P(EDOT-LD) and $\mathrm{P}(\mathrm{EDOT}-\mathrm{CD})$ films electrodeposited on AISI $316 \mathrm{~L}$ steel electrodes of $1 \times 0.5 \mathrm{~cm}^{2}$, which were incubated at $37^{\circ} \mathrm{C}$ in an orbital shaker at $60 \mathrm{rpm}$ in Eppendorf tubes with $1 \mathrm{~mL}$ of phosphate buffer saline (PBS, $\mathrm{pH}=7.2$ ) or Britton-Robinson buffer ( $\mathrm{BRB}, \mathrm{pH}=3.0)$. The release medium was changed and analyzed every $24 \mathrm{~h}$. For this purpose, the tubes were centrifuged at $13000 \mathrm{rpm}$ during $5 \mathrm{~min}$, and the supernatant was collected and stored at $4{ }^{\circ} \mathrm{C}$ to determine the concentration of released LD and CD through the phenol/ sulfuric acid procedure ${ }^{[42]}$ described above. All the release experiments were repeated three times to control the homogeneity of the results, and the released concentrations were averaged.

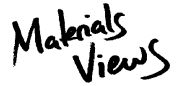

www.MaterialsViews.com
Macromol. Mater. Eng. 2012, 297, 359-368

(c) 2012 WILEY-VCH Verlag GmbH \& Co. KGaA, Weinheim 


\subsection{Cell Adhesion and Proliferation Assays}

In vitro adhesion and proliferation assays were performed using three different cellular lines of adherent growth: (i) cells HEp-2 (human line derived from an epidermoid carcinoma of larynx); (ii) cells DU145 (human line derived from a prostate carcinoma); and (iii) cells COS-7 (line derived of Cercopithecus aethiops-African green monkey-kidney and immortalized by transformation with SV40). HEp-2 and DU145 have an epithelial morphology while COS7 is a fibroblast-like cell line. These cellular lines have been selected because their manipulation and growth do not require special biological conditions, which explain their role as optimum target cells to study the biocompatibility and bioactivity of materials. Furthermore, the growth of these cells is faster than that of cells derived from primary cultures (e.g., nerve and cardiac cells).

Cells were plated in $25 \mathrm{~cm}^{2}$ tissue flasks and grown in Dulbecco's modified Eagle's medium (DMEM) supplemented with $10 \%$ fetal bovine serum (FBS), penicillin $\mathrm{G}\left(100 \mathrm{U} \cdot \mathrm{mL}^{-1}\right)$ and streptomycin $\left(100 \mathrm{mg} \cdot \mathrm{mL}^{-1}\right)$. The cultures were performed at $37^{\circ} \mathrm{C}$ and humid atmosphere with $95 \%$ air ( $5 \%$ carbon dioxide). Passage two cultures were used for experiments. Cellular confluent cultures were dissociated with $0.05 \%$ trypsin and $0.02 \%$ ethylenediamine tetraacetate (EDTA) in Hanks' balanced salt solution, harvested by centrifugation, and counted in Neubauer camera using $0.4 \%$ trypan blue.

The adhesion and proliferation assays were performed seeding $5 \times 10^{4}$ and $2 \times 10^{4}$ cells, respectively, from an appropriate cell suspension concentration with viability $>95 \%$. PEDOT and composite electrodeposited on $1 \mathrm{~cm}^{2}$ steel sheets were placed in 24-well plates, and subsequently sterilized by UV-radiation during $15 \mathrm{~min}$ in the laminar flow cabinet. Next, cells were seeded by covering $80-90 \%$ of the surface of each simple with cell suspension, which was slowly deposited with a pipette. In order to avoid a reduction of the seeding efficiency, no contact between cell suspensions and the sides of the wells was allowed. The plates were gently placed into an incubator to avoid agitation of the plate. After $1 \mathrm{~h}$, fresh medium $(1 \mathrm{~mL})$ was added into each well and the plate was returned to the incubator. Cultures to evaluate cellular adhesion and proliferation were incubated during $24 \mathrm{~h}$ and $7 \mathrm{~d}$, respectively. All experiments were repeated at least three times.

In order to evaluate the cell number in the samples, the following process was used. First, the medium of each well was changed by fresh medium supplemented with MTT [3-(4,5-dimethylthiazol-2yl)-2,5-diphenyltetrazolium; $5 \mathrm{mg} \cdot \mathrm{mL}^{-1}$ ] and the plate returned to the incubator for $3 \mathrm{~h}$. After this, the medium of each well was removed and the samples recoveries were placed in wells of a clean plate. The MTT reaction ${ }^{[43]}$ in the viable cells was determined by dissolving the formazan crystals in $1 \mathrm{~mL}$ of dimethyl sulfoxide (DMSO)/methanol/water (70:20:10 vol\%). According to this method, the absorbance at $540 \mathrm{~nm}$ was read in a spectrophotometer. ${ }^{[43]}$ The cells number was determined using a standard curve of $A_{540 \mathrm{~nm}}$ vs. number of viable cells. Analyses were carried out using the cell adherence density in each sample (number of cells $\cdot \mathrm{cm}^{-2}$ ).

To evaluate the cellular morphology, samples incubated with cells were fixed in $1 \mathrm{~mL}$ of $2.5 \%$ paraformaldehyde in PBS for $24 \mathrm{~h}$ at $4{ }^{\circ} \mathrm{C}$. Then, samples were progressively dehydrated using alcohols of $30,40,50,70,90,95$, and $100^{\circ}$ for $30 \mathrm{~min}$ at $4{ }^{\circ} \mathrm{C}$ in each one.
Finally, samples were coated by carbon sputtering for the observation in the scanning electronic microscope.

\section{Results and Discussion}

\subsection{Characterization of the Biocomposites}

Figure 1a compares the control voltammograms recorded in the potential range from -0.50 to $+1.40 \mathrm{~V}$ for PEDOT, $\mathrm{P}$ (EDOT-LD), and P(EDOT-CD). Results clearly indicate that the dextrins contained in the biocomposites obstruct the formation of polarons and bipolarons in PEDOT chains. The first anodic peak $\left(\mathrm{O}_{1}\right)$, which is identified as a small shoulder with $E_{\mathrm{p}}^{\mathrm{a}}\left(\mathrm{O}_{1}\right)=0.74 \mathrm{~V}$ for PEDOT, corresponds to the formation of polarons. This process is not detected in $\mathrm{P}$ (EDOT-LD) and $\mathrm{P}(\mathrm{EDOT}-\mathrm{CD})$ due to the blocking effect of the dextrins. The second anodic peak $\left(\mathrm{O}_{2}\right)$ with $E_{\mathrm{p}}^{\mathrm{a}}\left(\mathrm{O}_{2}\right)=1.29 \mathrm{~V}$ for PEDOT indicates the presence of bipolarons. These are formed through a process with low reversibility, as seen in the small reduction peak with $E_{\mathrm{p}}^{\mathrm{c}}\left(\mathrm{R}_{1}\right)=-0.16 \mathrm{~V}$ detected in the cathodic scanning. For P(EDOT-LD) and P(EDOT-CD) the $\mathrm{O}_{2}$ anodic peak shows $E_{\mathrm{p}}^{\mathrm{a}}\left(\mathrm{O}_{2}\right)=1.37$ and $1.28 \mathrm{~V}$, respectively, suggesting that the behavior of the latter biocomposite looks closer to that of PEDOT. The cathodic scan shows a reduction peak $R_{1}$ with $E_{p}^{c}\left(R_{1}\right)=-0.25$ and $-0.23 \mathrm{~V}$ for $\mathrm{P}(\mathrm{EDOT}-\mathrm{LD})$ and $\mathrm{P}(\mathrm{EDOT}-\mathrm{CD})$, respectively, which corresponds to a reduction of a small concentration of the
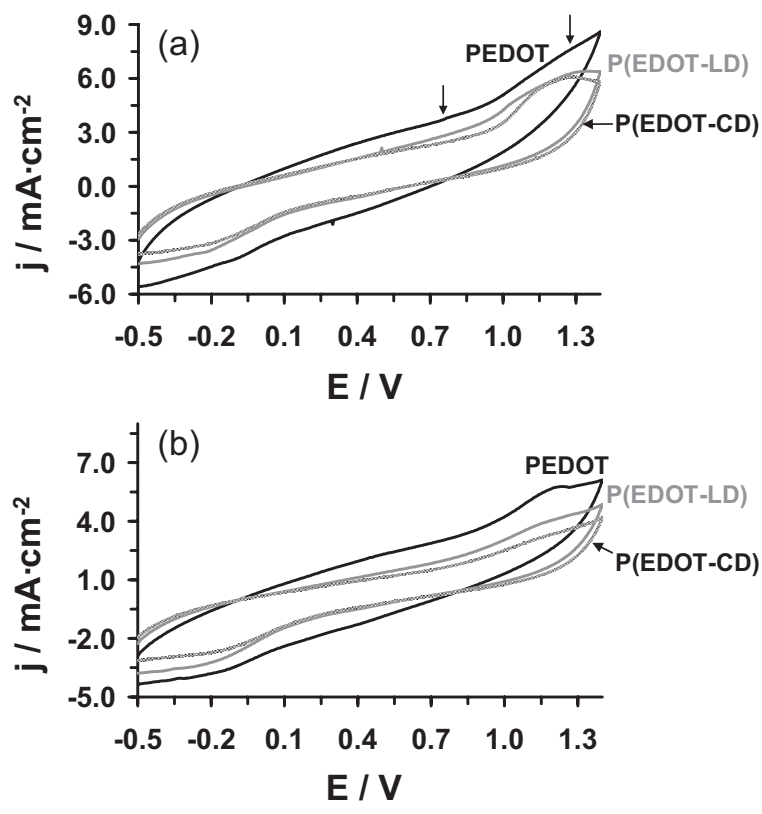

Figure 1. Control voltammograms for the oxidation of PEDOT, $P(E D O T-L D)$, and P(EDOT-CD) films. The vertical arrows indicate the two anodic peaks of PEDOT. (b) Control voltammograms for the oxidation of PEDO, P(EDOT-LD) and P(EDOT-CD) films after 30 consecutive cycles of oxidation-reduction. 
bipolaron formed in the anodic scan. The variation of the anodic and cathodic peak potentials is fully consistent with the current densities ( $j$ in Figure $1 a$ ), which indicates that the concentration of oxidized molecules is larger for PEDOT than for the biocomposites.

The voltammograms recorded after 30 consecutive oxidation-reduction cycles $\left(n_{\text {ox-red }}=30\right)$, which are displayed in Figure $1 b$, indicate a drastic reduction of the electroactivity, especially for the biocomposites. Furthermore, the current density decreases drastically for the three materials evidencing that electrochemical degradation produces a significant reduction in the concentration of oxidized CP chains. The electrostability of the three materials is analyzed in Figure 2, which compares the variation of the electroactivity against $n_{\text {ox-red. }}$ The electroactivity of PEDOT, which presents the highest electrochemical stability, decreases $30 \%$ after 30 consecutive redox cycles, whereas that of $\mathrm{P}(\mathrm{EDOT}-\mathrm{LD})$ and $\mathrm{P}(\mathrm{EDOT}-\mathrm{CD})$ reduces by 43 and 52\%, respectively. Indeed, the electroactivity of the two biocomposites undergoes a reduction of $\approx 25 \%$ after five consecutive redox cycles only, showing the negative effects of the dextrins in the electrostability of PEDOT (i.e., the electroactivity of PEDOT decreases by $\approx 5 \%$ after five consecutive redox cycles).

Nyquist impedance plots of PEDOT and the two biocomposites over a frequency range of $0.05-20 \mathrm{~Hz}$ are shown in Figure 3. The impedance spectra show a single semicircle in the high frequency region and a nearly vertical line in the low frequency region, which indicate that the electrode process is controlled by electrochemical reaction at high frequencies and by mass transfer at low frequencies. The incorporation of dextrins produces a significant enhancement of the capacitance and the resistance. These effects are more important in P(EDOT-LD), which presents the highest resistance, than in $\mathrm{P}$ (EDOT-CD).

The electrical conductivity of perchlorate-doped PEDOT films generated in aqueous solution at $1.10 \mathrm{~V}$ was measured applying the sheet resistance method to dry films. The resulting conductivity, $\sigma=5 \mathrm{~S} \cdot \mathrm{cm}^{-1}$, is two orders of

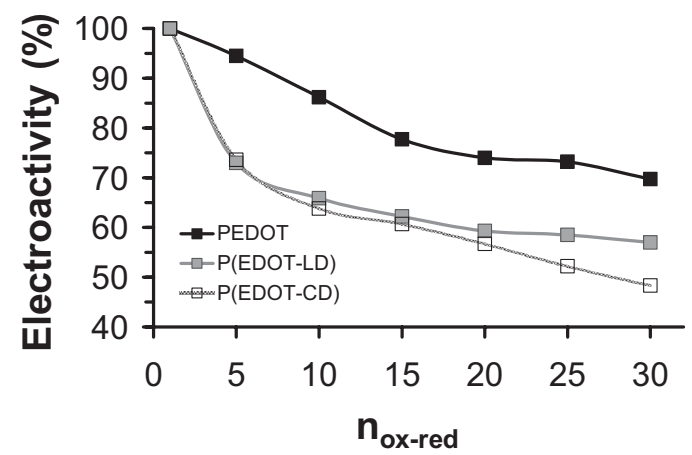

Figure 2. Evolution of the electroactivity (in \%) against the number of consecutive oxidation-reduction cycles $\left(n_{\text {ox-red }}\right)$ for PEDOT, $\mathrm{P}(\mathrm{EDOT}-\mathrm{LD})$, and $\mathrm{P}(\mathrm{EDOT}-\mathrm{CD})$.

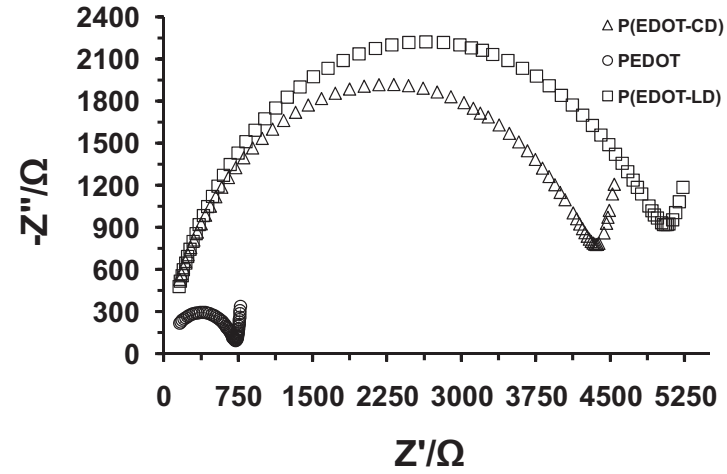

Figure 3. Nyquist impedance plots of PEDOT, P(EDOT-LD), and $\mathrm{P}(\mathrm{EDOT}-\mathrm{CD})$.

magnitude smaller than that obtained for perchloratedoped PEDOT films generated in acetonitrile solution at $1.40 \mathrm{~V}\left(\sigma=315 \mathrm{~S} \cdot \mathrm{cm}^{-1}\right),{ }^{[44]}$ the latter being determined using the same procedure. Interestingly, the incorporation of $\mathrm{LD}$ and $\mathrm{CD}$ does not alter significantly the electrical conductivity of the $\mathrm{CP}$, the values measured for dry P(EDOTCD) and P(EDOT-LD) films being $\sigma=3$ and $1 \mathrm{~s} \cdot \mathrm{cm}^{-1}$. This similarity suggests that dextrins do not produce drastic structural changes at the bulk.

Figure 4 compares the $5 \times 5 \mu \mathrm{m}^{2}$ topographic AFM images of PEDOT, $\mathrm{P}$ (EDOT-LD), and P(EDOT-CD). As it can be seen, $\mathrm{LD}$ and $\mathrm{CD}$ provoke different changes on the topography of the PEDOT surface. Thus, the globular surface of the pure PEDOT films transforms into the powdery and layered topographies of $\mathrm{P}(\mathrm{EDOT}-\mathrm{LD})$ and $\mathrm{P}(\mathrm{EDOT}-\mathrm{CD})$, respectively. This difference should be attributed to the polymeric and oligomeric nature of $\mathrm{LD}$ and $\mathrm{CD}$, respectively, which affect the molecular aggregates formed by the two biocomposites. Molecular aggregates are significantly smaller in P(EDOT-LD) than in PEDOT, which results in the powdery topography displayed in Figure $4 \mathrm{~b}$. In contrast, larger aggregates are identified for P(EDOT-CD) than for PEDOT, explaining the transformation of the globular morphology found for the latter (Figure 4a) into the layered structure identified for the former (Figure 4c). On the other hand, the average roughness was lower for PEDOT $(r=63 \mathrm{~nm})$ than for P(EDOT-LD) $(r=76 \mathrm{~nm})$ and P(EDOT$\mathrm{CD})(r=105 \mathrm{~nm})$, indicating that the effect of the dextrins in the topological levels of the CP molecules is moderate but not negligible. Similar features are observed in the highand low-resolution SEM micrographs displayed in Figure 5. Dextrins affect the globular morphology of the PEDOT surface (Figure $5 \mathrm{a}$ ), even though the changes induced by LD and $\mathrm{CD}$ are different (Figure $5 \mathrm{~b}$ and $\mathrm{c}$, respectively). However, the relative similitude between PEDOT and $\mathrm{P}$ (EDOT-CD) suggests that the cyclic oligosaccharide is homogeneously distributed in the polymeric matrix, producing only small changes in the morphology and

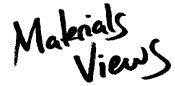

www.MaterialsViews.com 
(a)
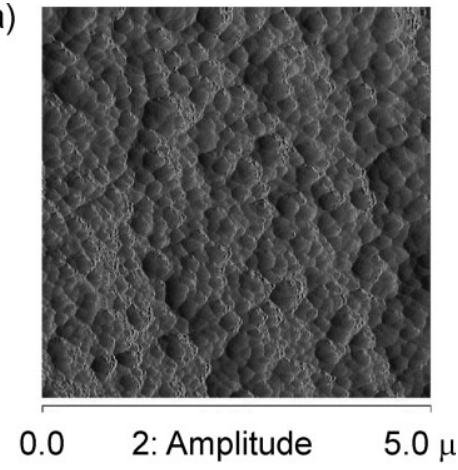

(b)

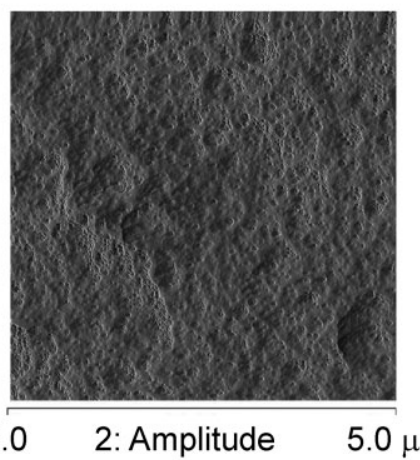

(c)

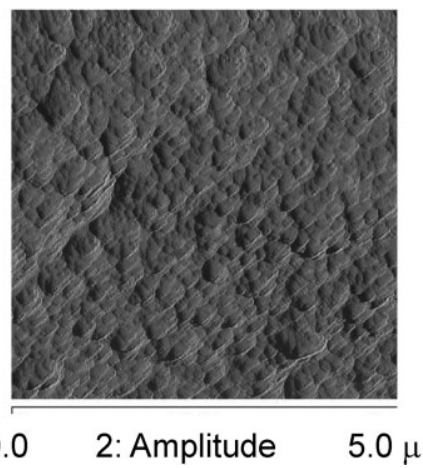

Figure 4. Topograhic AFM images of: (a) PEDOT, (b) P(EDOT-LD), and (c) $P(E D O T-C D)$.

topology because of its small size. Moreover, Figure 5 evidences that the porosity of the two biocomposites is lower than that of PEDOT, which is consistent with the lower electroactivity of the biocomposites (Figure 1).

Results displayed in Figure 4 and 5 are fully consistent with the energy dispersive EDX spectroscopy analyses performed at the surface of PEDOT, P(EDOT-LD), and $\mathrm{P}(\mathrm{EDOT}-\mathrm{CD}$ ) films (Table 1). Thus, quantitative elemental analyses of $\mathrm{C}, \mathrm{O}, \mathrm{S}$, and $\mathrm{Cl}$ suggest different chemical compositions for $\mathrm{P}$ (EDOT-LD) and P(EDOT-CD). The concentration of $\mathrm{S}$ and $\mathrm{C}$ is considerably smaller and larger, respectively, in $\mathrm{P}(\mathrm{EDOT}-\mathrm{LD})$ than in PEDOT. This feature suggests that the LD is mainly located at the surface, which is consistent with the powdery morphology of the biocomposite. On the other hand, the composition of $\mathrm{P}$ (EDOT-CD) and PEDOT are relatively similar. (a)

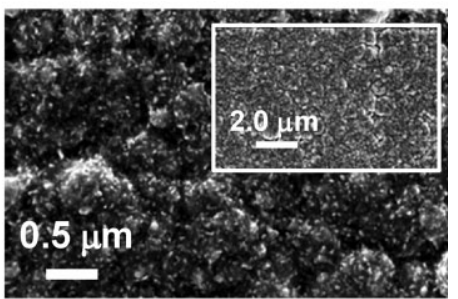

(b)

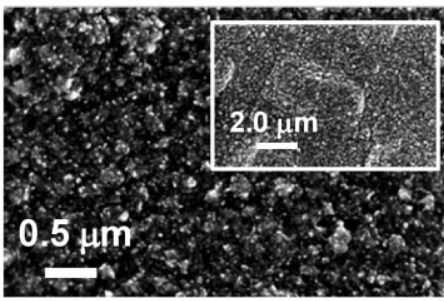

(c)

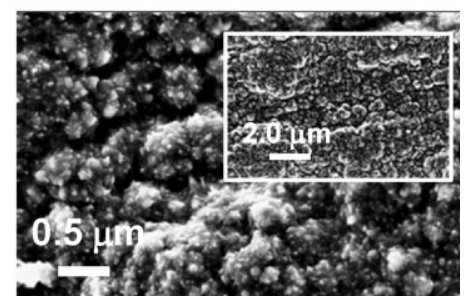

Figure 5. High- and low-resolution (inset) SEM micrographs of: (a) PEDOT, (b) P(EDOT-LD), and (c) P(EDOT-CD).

The contact angles of PEDOT, P(EDOT-LD), and P(EDOT$\mathrm{CD}$ ) films have been determined to illustrate the morphological changes induced by dextrins on the wettability of the films. In general, dextrins are usually considered to be highly hydrophilic since they contain no obvious apolar moieties but a large number of hydroxyl groups. The contact angle of PEDOT at room temperature is $\theta=54.0 \pm 0.6^{\circ}$, decreasing to $\theta=46.9 \pm 0.9^{\circ}$ and $52.1 \pm 0.7^{\circ}$ after incorporation of $\mathrm{LD}$ and $\mathrm{CD}$, respectively. Thus, the reduction of the hydrophobicity at the surface of the composites with respect to that of PEDOT is significantly higher in $\mathrm{P}(\mathrm{EDOT}-\mathrm{LD})$ than in $\mathrm{P}(\mathrm{EDOT}-\mathrm{CD})$. These results are fully consistent with the SEM and AFM images reflecting that the structural changes produced by the $\mathrm{CD}$ are

Table 1. Composition (concentration of $\mathrm{C}, \mathrm{O}, \mathrm{S}$, and $\mathrm{Cl}$ ) obtained by EDX spectroscopy analyses at the surface of PEDOT, P(EDOT-LD), and $P(E D O T-C D)$ films.

\begin{tabular}{lrrrr}
\hline \multirow{2}{*}{ Sample } & \multicolumn{4}{c}{$\begin{array}{c}\text { Composition } \\
\text { [wt\%] }\end{array}$} \\
\cline { 2 - 5 } & C & O & \multicolumn{1}{c}{ S } & Cl \\
\hline PEDOT & 46.0 & 29.5 & 19.7 & 4.8 \\
P(EDOT-LD) & 58.2 & 29.6 & 9.4 & 2.8 \\
P(EDOT-CD) & 43.0 & 30.9 & 17.6 & 8.5
\end{tabular}


relatively small, whereas the LD alters considerably the structure of PEDOT at the surface. Moreover, the concentration of dextrins in the composite was found to be slightly larger for $\mathrm{P}(\mathrm{EDOT}-\mathrm{LD})$ than for $\mathrm{P}(\mathrm{EDOT}-\mathrm{CD})$ (see below).

\subsection{Content and Release of Dextrins}

The phenol/sulfuric acid method described in the Experimental Section, was used to quantify the concentration of dextrins in the P(EDOT-LD) and P(EDOT/ $\mathrm{CD}$ ) composites prepared in this work, which was found to be 20 and 15 wt\%, rrespectively. On the other hand, Figure 6 represents the cumulative dextrins release considering two different media, i.e., $\operatorname{BRB}(\mathrm{pH}=3)$ and PBS $(\mathrm{pH}=7.2)$. These releasing curves have been analyzed using four different models: zero order kinetic model, first-order kinetic model, Higuchi model, ${ }^{[45]}$ and Korsmeyer-Peppas model. ${ }^{[46]}$ The fitted parameters are listed in Table 2. As it can be seen, the release occurs in the first $4 \mathrm{~d}$ of incubation independently of both the $\mathrm{pH}$ and the biocomposite, a plateau being reached in all cases after such incubation period. The release of a molecule entrapped in polymeric matrix is typically controlled by the diffusion through the matrix, the degradation of matrix and the strength of the intermolecular interactions. ${ }^{[4,48]}$

Results evidence the large influence of the $\mathrm{pH}$ on the $\mathrm{CD}$ releasing process. Thus, in acidic conditions most of the $C D$ (76\%) was effectively released from the composite after $96 \mathrm{~h}$, while the releasing of LD reduced to $32 \%$. In contrast, the release of dextrin was similar and relatively low (i.e., 32 and $36 \%$ for $\mathrm{CD}$ and $\mathrm{LD}$, respectively) at $\mathrm{pH}=7.2$. PEDOT chains are expected to form stronger intermolecular interactions with $\mathrm{LD}$ than with $\mathrm{CD}$ due to the polymeric nature of the former. Accordingly, the release of $C D$ from $\mathrm{P}(\mathrm{EDOT}-\mathrm{CD})$ is expected to be significantly higher than the release of LD from $\mathrm{P}$ (EDOT-LD), as was observed in BRB. However, dextrins tend to self-aggregate at neutral $\mathrm{pH}$,
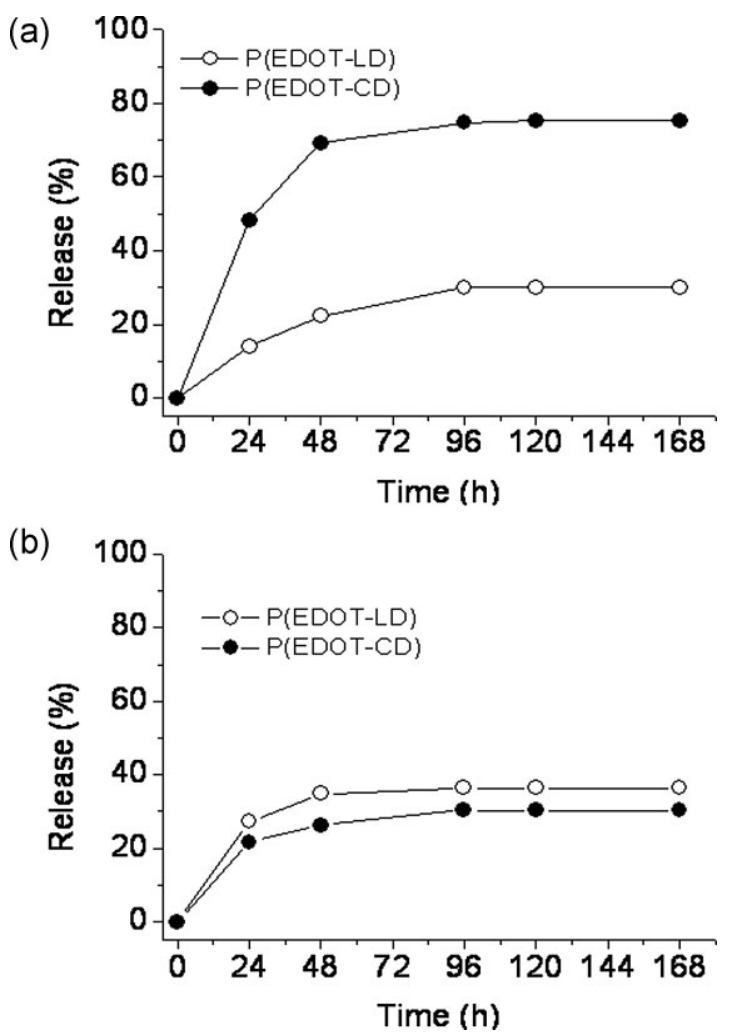

Figure 6. Cumulative release of $C D$ and $L D$ from $P(E D O T-C D)$ and $\mathrm{P}(\mathrm{EDOT}-\mathrm{LD})$ samples, respectively, incubated in (a) $\mathrm{BRB}(\mathrm{pH}=3.0)$ and (b) PBS $(\mathrm{pH}=7.2)$.

making difficult the diffusion of the $\mathrm{CD}$ molecules for their releasing in PBS. ${ }^{[49]}$ In opposition, the hydroxyl group protonation produced by the strong acidic medium increases the hydrophilic character. This reduces the surface activity and enhances the releasing in BRB. The influence of this pH-effect is relatively low in $\mathrm{P}$ (EDOT-LD) since, in this case, the biocomposite is dominated by the interactions between two polymeric systems.

Table 2. Parameters of the release kinetics based on four different models. Releasing assays were carried out in $\mathrm{PBS}(\mathrm{pH}=7.2)$ and in $\mathrm{BRB}$ $(\mathrm{pH}=3.9) \cdot M_{\mathrm{t}} / M_{\infty}$ is the cumulative percentage of dextrin release. 100- $\left(M_{\mathrm{t}} / M_{\infty}\right)$ corresponds to the percentage of dextrin remaining in the matrix. $k, t, n$, and $r^{2}$ correspond to the rate constant, the time, the parameter to consider the morphological characteristic of the substrate (see text), and the square of the regression coefficient, respectively.

\begin{tabular}{|c|c|c|c|c|c|c|c|c|c|c|c|}
\hline \multirow{3}{*}{$\begin{array}{l}\text { Release } \\
\text { medium }\end{array}$} & \multirow[t]{3}{*}{ Composite } & \multirow{2}{*}{\multicolumn{2}{|c|}{$\frac{\text { Zero-order }}{M_{\mathrm{t}} / \mathbf{M}_{\infty}=k t}$}} & \multicolumn{3}{|c|}{ First-order } & \multicolumn{2}{|c|}{ Higuchi } & \multicolumn{3}{|c|}{ Korsmeyer-Peppas } \\
\hline & & & & \multicolumn{3}{|c|}{$100-\left(M_{t} / M_{\infty}\right)=k t^{n}$} & \multicolumn{2}{|c|}{$M_{t} / M_{\infty}=k t^{1 / 2}$} & \multicolumn{3}{|c|}{$M_{t} / M_{\infty}=k t^{n}$} \\
\hline & & $\begin{array}{c}k_{0} \\
{\left[h^{-1}\right]}\end{array}$ & $r^{2}$ & $\begin{array}{c}k_{1} \\
{\left[h^{-1}\right]}\end{array}$ & $n$ & $r^{2}$ & $\begin{array}{c}k_{\mathrm{H}} \\
{\left[\mathbf{h}^{-1}\right]}\end{array}$ & $r^{2}$ & $\begin{array}{l}k_{\mathrm{KP}} \\
{\left[\mathrm{h}^{-1}\right]}\end{array}$ & $n$ & $r^{2}$ \\
\hline \multirow[t]{2}{*}{ PBS $(p H=7.2)$} & P(EDOT-LD) & 0.4805 & 0.4376 & 1.0016 & 0.1026 & 0.9900 & 4.3485 & 0.8871 & 1.1712 & 0.8451 & 0.9530 \\
\hline & $\mathrm{P}(\mathrm{EDOT}-\mathrm{CD})$ & 0.3889 & 0.5252 & 1.0013 & 0.0791 & 0.9996 & 3.4931 & 0.9258 & 1.1471 & 0.7936 & 0.9601 \\
\hline \multirow[t]{2}{*}{$\mathrm{BRB}(\mathrm{pH}=3.0)$} & P(EDOT-LD) & 0.3536 & 0.8467 & 1.0188 & 0.0718 & 0.9144 & 3.0725 & 0.9963 & 1.0575 & 0.7682 & 0.9921 \\
\hline & $\mathrm{P}$ (EDOT-CD) & 0.9646 & 0.5761 & 1.0619 & 0.2999 & 0.9506 & 8.6291 & 0.9367 & 1.1881 & 1.0109 & 0.9602 \\
\hline
\end{tabular}

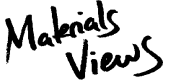

www.MaterialsViews.com 
Table 2 shows the parameters derived from the different kinetic models. As it can be seen, the correlation coefficients $\left(r^{2}\right)$ provided by the zero-order model are, in general, very poor. In opposition, the first-order model led to very high $r^{2}$ values, especially in PBS, indicating a relationship between the releasing rate and the concentration of dextrins. Furthermore, the first-order model introduces the parameter $n$ to describe the morphological characteristics of the material (i.e., porous materials present $n<0.5$ ). Good correlations were also identified for the Higuchi's model, ${ }^{[45]}$ which reflects the dependence of the release of dextrins with the square root of time (i.e., diffusive process). Finally, the Korsmeyer-Peppas model, ${ }^{[46]}$ which provides good correlations for both BRB and PBS environments, combines the dextrins release and the morphology of the matrix. In the latter model, the coefficient $n$ fits to values larger than 0.5 in all cases suggesting a compact morphology.

\subsection{Cellular Adhesion and Proliferation}

The utility of the two dextrin-containing biocomposites in biotechnological applications based on regeneration of tissues has been examined by analyzing cellular adhesion and proliferation on films. Assays were performed considering three different lines of eukaryotic cells: HEp-2, DU145, and COS-7. The former two are epithelial-like cell lines, while the later is a fibroblast-like cell line. Both PEDOT and tissue-culture polystyrene (TCPS) have been used as control substrates.

Quantitative results of cellular adhesion are displayed in Figure $7 \mathrm{a}$. The number of cells by area of material observed on the biocomposites is larger than on the control substrates, independently of the cell line. Thus, incorporation of dextrins to PEDOT promotes cell adhesion, this feature being especially remarkable for the Hep-2 and DU145 cells (i.e., adhesion of these epithelial-like cells on PEDOT is lower than that of COS-7). On the other hand, Figure $7 \mathrm{a}$ reveals that the adhesion of cells on P(EDOT-LD) films is significantly higher than on $\mathrm{P}(\mathrm{EDOT}-\mathrm{CD})$. This observation should be attributed to the fact that the cells have a direct contact with the polysaccharide, which has been hypothesized to be mainly located at the surface, whereas the impact of the CD on the cells is lower because of its homogeneous distribution.

The number of viable cells per unit of material after $7 \mathrm{~d}$ of culture (i.e., proliferation on the material) is displayed in Figure $7 \mathrm{~b}$ for the four tested substrates. In all cases, there is a significant increment in the amount of cells with respect to those obtained after $24 \mathrm{~h}$ of culture (Figure $7 \mathrm{a}$ ). Again, the number of cells adhered to the two biocomposites is higher than those adhered to the control substrates, independently of the cell line, supporting the fact that the dextrins produce a benefit in terms of biocompatibility. However, the number of cells adhered to P(EDOT-CD) is higher than that (a)

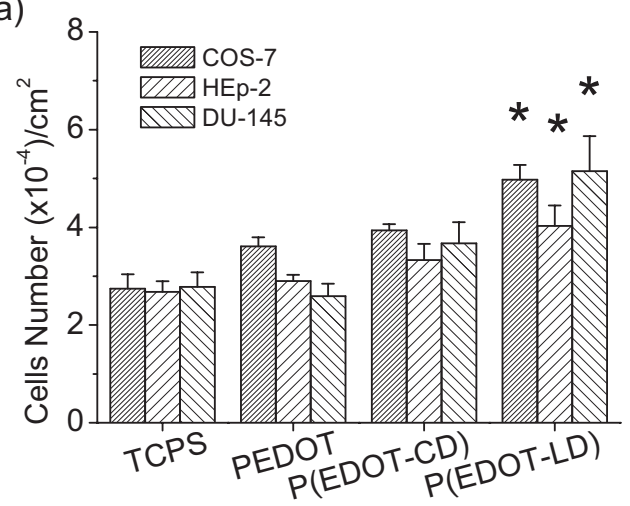

(b)

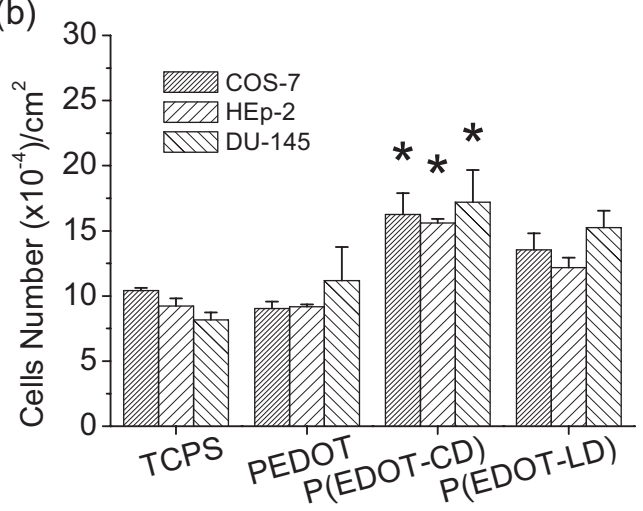

Figure 7. Cellular adhesion (a) and cellular proliferation (b) on the surface of the investigated biocomposites. Values were normalized with respect to the area of material. PEDOT and TCPS were used as control substrates. Bars represent the mean \pm standard deviation. The asterisk $\left({ }^{*}\right)$ indicates a significant difference with the control TCPS, Tukey's test $(p<0.05)$.

observed for P(EDOT-LD). This feature suggests that once the cells are adhered to the biocomposite, the activity and proliferation of the cells is promoted by small CD molecules which facilitate the $\mathrm{CP} /$ cell and cell/cell recognition.

SEM micrographs displayed in Figure 8, which were taken after $7 \mathrm{~d}$ of culture, show details of the adhesion of COS-7 cells to PEDOT, P(EDOT-CD), and P(EDOT-LD). The connection sites between the cells and the surface or between two cells have been marked with arrows. As it can be seen, in general, there is a significant spreading of cells on the surface of the substrates. Details showing the stress fibers formed by the cells to move along the substrates are displayed in Figure $8 \mathrm{a}$ and $\mathrm{b}$ (inset). These correspond to the lamellipodia, which are delicate sheet-like extension of cytoplasm that form transient adhesions with the substrate, and the actin filaments known as filopodia. The formation of filopodia is less abundant on the P(EDOT-CD) surface (Figure $8 \mathrm{c}$ and $\mathrm{d}$ ) than on the $\mathrm{P}$ (EDOT-LD) one (Figure 8e-g). It should be emphasized that the abundance and distribution of filopodia on the surfaces is independent 

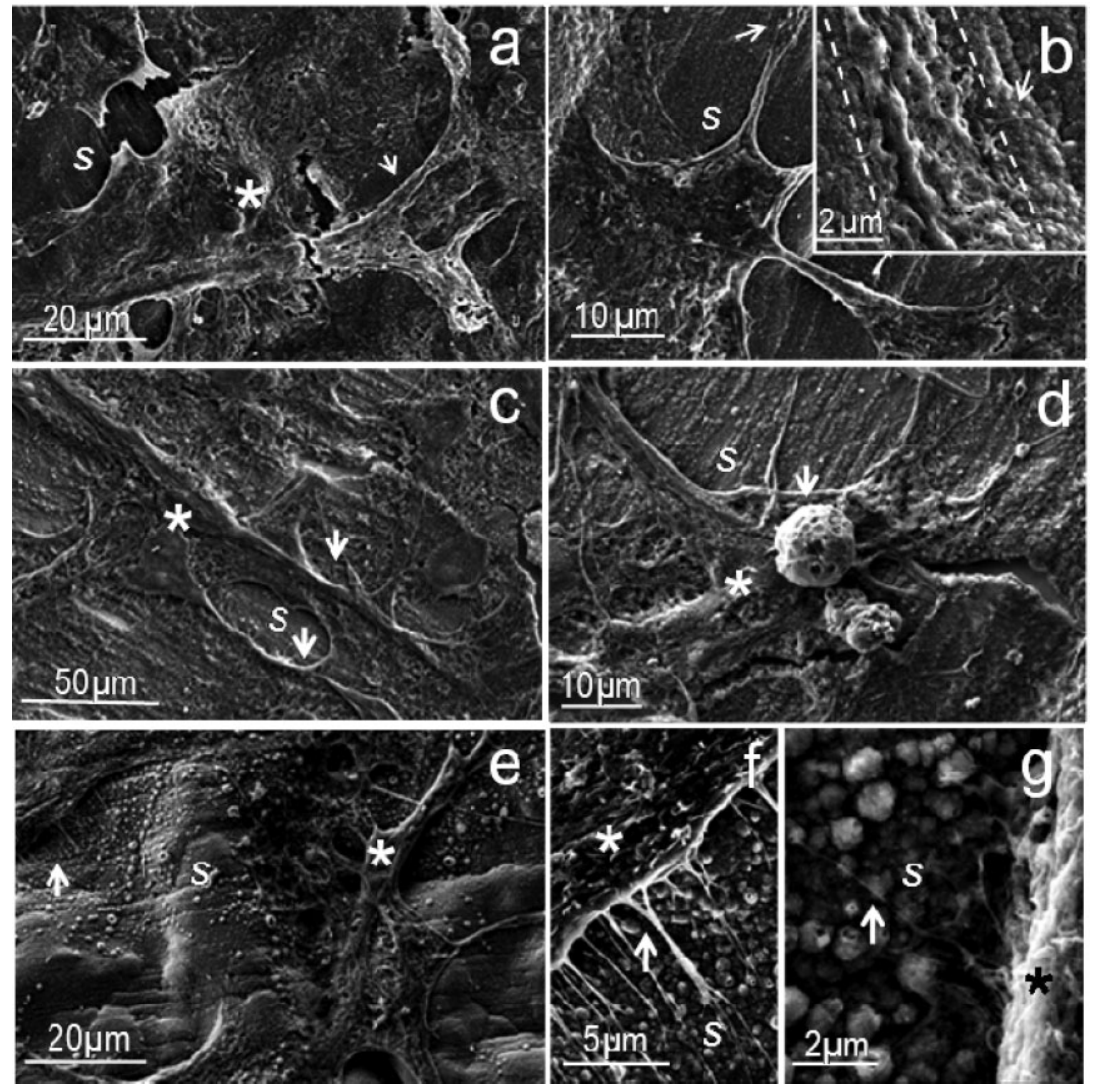

Figure 8. Cellular adhesion of cells COS-7 (fibroblast type) onto PEDOT (a, b), P(EDOT-CD) (c, d), and P(EDOT-LD) (e, g) substrates. Micrographs were taken after $7 \mathrm{~d}$ of culture. The cells adhered on the surface $(s)$ are shown with asterisk $\left(^{*}\right)$, while the arrows indicate connections or interactions between the cell and the surface or between two cells. produce significant changes in the bulk. Inspection to the topographies and morphologies indicates that the globular surface of PEDOT transforms into a powdery surface upon the incorporation of LD. The influence of the $\mathrm{CD}$, which changes the aspect of the surface from globular to layered, is less drastic. These observations combined with the EDX elemental analyses suggest that the LD mainly concentrates at the surface of the films, while the $\mathrm{CD}$ is homogeneously distributed in the composite.

The concentration of $\mathrm{CD}$ and $\mathrm{LD}$ in $\mathrm{P}$ (EDOT-CD) and P(EDOT-LD) has been found to be 15 and $20 \%$, respectively. The releasing of the $\mathrm{CD}$ from the biocomposite depends significantly on the environment, which has been attributed to the aggregation effects at neutral $\mathrm{pH}$ and the increase of hydrophilic character at low $\mathrm{pH}$. In contrast, no $\mathrm{pH}$ dependence was found in the releasing of LD from $\mathrm{P}($ EDOT-LD). This is because the latter biocomposite is dominated by strong interactions between the polysaccharide and PEDOT chains. On the other hand, cell adhesion and proliferation assays have been performed considering three different cellular lines: two epithelial-like and one fibroblast-like. Results clearly indicate that the two biocomposites behave of the relative bioactivity of the two substrates, cellular proliferation being found to be higher in $\mathrm{P}$ (EDOT-CD) than in $\mathrm{P}(\mathrm{EDOT}-\mathrm{LD}$ ) (Figure 7b). In spite of this, Figure 8d shows a cell without any evident connection to P(EDOT-CD) surface (arrow mark), evidencing that adhesion of the cell with filopodia is much less apparent in the latter biocomposite.

\section{Conclusion}

$\mathrm{P}$ (EDOT-LD) and $\mathrm{P}(\mathrm{EDOT}-\mathrm{CD})$ biocomposites have been prepared electrochemically in water using mixtures of EDOT monomer and the corresponding dextrin. Both the electroactivity and the electrostability of the two biocomposites are considerably lower than those of PEDOT. This is because the incorporation of dextrins promotes the formation of compact structures, reducing the porosity. Consequently, the access and escape of dopant ions upon oxidation and reduction processes, respectively, become more difficult in the biocomposites than in PEDOT films. In contrast, the electrical conductivities of the biocomposites are similar to that of PEDOT, suggesting that dextrins do not as a cellular matrix. Thus, the incorporation of dextrins significantly improves the cellular activity of PEDOT.

Typically, cellular activity is promoted by substrates with porous morphologies since nutrients availability grows with the porosity. However, in this work we found that the bioactivity of both $\mathrm{P}$ (EDOT-LD) and P(EDOT-CD) is higher than that of PEDOT, even though the morphologies the latter CP. This should be attributed to the role of dextrins, which facilitate the interaction between the surface and the cells. Furthermore, results presented in this work allow us to conclude that $\mathrm{P}(\mathrm{EDOT}-\mathrm{CD})$, which shows biocomposite for the fabrication of cellular platforms with good electrical properties. Thus, the role of the $C D$ is to facilitate and promote the $\mathrm{CP} / \mathrm{cell}$ recognition process enhancing the cellular proliferation with respect to neat PEDOT but without detriment of the electrical conductivity.

Acknowledgements: Financial support from the MICINN and FEDER (MAT2009-09138) and Generalitat de Catalunya (research of the two former biocomposites are less porous than that of higher bioactivity than $\mathrm{P}(\mathrm{EDOT}-\mathrm{LD})$, is a very promising

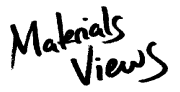

www.MaterialsViews.com
Macromol. Mater. Eng. 2012, 297, 359-368

(C) 2012 WILEY-VCH Verlag GmbH \& Co. KGaA, Weinheim 
group 2009 SGR 925 and XROTC) is gratefully acknowledged. B.T.-D. acknowledges support from the MICINN through an FPI grant and financial support for his stay at the 3B's Research Group (Portugal). The support from project PTDC/FIS/115048/2009 (FCTPortugal) is also acknowledged. Authors are indebted to Dr. Elaine Armelin for helpful suggestions and to David Aradilla for assistance in electrical measures and SEM micrographs. Support for the research of C.A. was received through the prize "ICREA Academia" for excellence in research funded by the Generalitat de Catalunya.

Received: May 25, 2011; Revised: July 25, 2011; Published online: November 3, 2011; DOI: 10.1002/mame.201100180

Keywords: biocompatibility; cellular activity; conducting polymers; poly(3,4-ethylenedioxythiophene) (PEDOT); polysaccharides

[1] M. Dietrich, J. Heinze, G. Heywang, F. Jonas, J. Electroanal. Chem. 1994, 369, 87.

[2] C. J. Brabec, N. S. Sariciftci, J. C. Hummelen, Adv. Funct. Mater. 2001, 11, 15.

[3] L. Groenendaal, F. Jonas, V. Freitag, H. Pielartzik, J. R. Reynolds, Adv. Mater. 2000, 12, 481.

[4] L. Groenendaal, G. Zotti, P.-H. Aubert, S. M. Waybright, J. R. Reynolds, Adv. Mater. 2003, 15, 855.

[5] A. Menaker, V. Syritski, J. Reut, A. Opik, V. Horvath, R. E. Gyurcsanvi, Adv. Mater. 2009, 21, 2271.

[6] H. Yoon, S. K. Lee, O. S. Kwon, H. S. Song, E. H. Oh, T. H. Park, J. Jang, Angew. Chem., Int. Ed. 2009, 48, 2755.

[7] K. J. Gilmore, M. Kita, Y. Han, A. Gelmi, M. J. Higgins, S. E. Moulton, G. M. Clark, R. Kapsa, G. G. Wallace, Biomaterials 2009, 30, 5292.

[8] L. B. Liu, M. H. Yu, X. R. Duan, S. Wang, J. Mater. Chem. 2010, 20, 6942.

[9] C. Ocampo, E. Armelin, F. Estrany, L. J. del Valle, R. Oliver, F. Sepulcre, C. Alemán, Macromol. Mater. Eng. 2007, 292, 85.

[10] C. Alemán, B. Teixeira-Dias, D. Zanuy, F. Estrany, E. Armelin, L. J. del Valle, Polymer 2009, 50, 1965.

[11] B. Teixeira-Dias, D. Zanuy, L. J. del Valle, F. Estrany, E. Armelin, C. Alemán, Macromol. Chem. Phys. 2010, 211, 1117.

[12] K. Krishnamoorthy, R. S. Gokhale, A. Q. Contractor, A. Kumar, Chem. Commun. 2004, 40, 820.

[13] S. C. Luo, S. S. Liour, H. H. Yu, Chem. Commun. 2010, 46, 4731.

[14] L. J. del Valle, D. Aradilla, R. Oliver, F. Sepulcre, A. Gamez, E. Armelin, C. Alemán, F. Estrany, Eur. Polym. J. 2007, 43, 2342.

[15] C. Salto, E. Saindon, M. Bolin, A. Kanciurzewska, M. Fahlman, E. W. H. Jager, P. Tengvall, E. Arenas, M. Berggren, Langmuir 2008, 24, 14133.

[16] L. J. del Valle, F. Estrany, E. Armelin, R. Oliver, C. Alemán, Macromol. Biosci. 2008, 8, 1144.

[17] K. Svennersten, M. H. Bolin, E. W. H. Jager, M. Berggren, A. Richter-Dahfors, Biomaterials 2009, 30, 6257.
[18] Y. Xiao, C. M. Li, S. Wang, J. Shi, C. P. Ooi, J. Biomed. Mater. Res. 2010, 92A, 766.

[19] H. Xie, S.-C. Luo, H-h. Yu, Small 2009, 5, 2611.

[20] B. D. Martin, L. M. Velea, C. M. Soto, C. M. Whitaker, B. P. Gaber, B. Ratna, Nanotechnology 2007, 18, 055103.

[21] P. M. Bersier, J. Bersier, B. Klingert, Electroanalysis 1991, 3, 443.

[22] Comprehensive Supramolecular Chemistry, Vol. 3: Cyclodextrins, (Eds., J. Szejtli, T. Osa), Elsevier, Oxford 1996.

[23] A. Ferancová, J. Labuda, J. Anal. Chem. 2001, 370, 1.

[24] A. Harada, Acc. Chem. Res. 2001, 34, 456.

[25] O. R. Chen, C. Liu, F. O. Liu, Prog. Chem. 2010, 22, 927.

[26] C. Lagrost, K. I. Chane-Ching, J.-C. Lacroix, S. Aeiyach, M. Jouini, P.-C. Lacaze, J. Tanguy, J. Mater. Chem. 1999, 9, 2351.

[27] C. Lagrost, M. Jouini, J. Tanguy, S. Aeiyach, J.-C. Lacroix, K. I. Chane-Ching, P. C. Lacaze, Electrochim. Acta 2001, 46, 3985.

[28] T. Shimomura, K. I. Yoshida, K. Ito, H. Reinosuke, Polym. Adv. Technol. 2000, 11, 837.

[29] K. I. Yoshida, K. Shimomura, K. Ito, R. Hayakawa, Langmuir 1999, 15, 910.

[30] D. A. Reece, S. F. Ralph, G. G. Wallace, J. Membr. Sci. 2005, 249, 9.

[31] J. Arjomandi, R. Holze, Eur. J. Chem. 2008, 8, 199.

[32] J. Arjomandi, R. Holze, J. Solid State Electrochem. 2007, 11, 1093.

[33] K. R. Temsamani, H. B. Mark, Jr., W. Kutner, A. M. Stalcup, J. Solid State Electrochem. 2002, 6, 391.

[34] M. Van den Boogaard, G. Bonnet, P. van't Hof, Y. Wang, C. Brochon, P. van Hutten, A. Lapp, G. Hadziioannou, Chem. Mater. 2004, 16, 4383.

[35] V. S. Vasantha, K. L. N. Phani, J. Electroanal. Chem. 2002, 520, 79.

[36] V. S. Vasantha, R. Thangamuthu, S.-M. Chen, Electroanalysis 2008, 20, 1754.

[37] M. Dubs, J. Weisser, R. Linke, A. Pfuch, D. Imhof, M. Schnabelrauch, Materialwiss. Werkstofftech. 2009, 40, 853.

[38] J. Carvalho, S. Moreira, J. Maia, F. M. Gama, J. Biomed. Mater. Res. 2010, 93A, 389.

[39] J. Hardwicke, R. Moseley, P. Stephens, K. Harding, R. Duncan, D. W. Thomas, Mol. Pharm. 2010, 7, 699.

[40] S. M. Moreira, F. K. Andrade, L. Domingues, M. Gama, BMC Biotechnol. 2008, 8, 78.

[41] J. Carrasco, E. Brillas, V. Fernández, P. L. Cabot, J. A. Garrido, F. Centellas, R. M. Rodríguez, J. Electrochem. Soc. 2001, 148, E19.

[42] M. Dubois, K. A. Guilles, P. A. Hamilton, P. A. Rebers, F. Smith, Anal. Chem. 1956, 28, 350.

[43] T. Mosmann, J. Immunol. Methods 1983, 65, 55v.

[44] C. Ocampo, R. Oliver, E. A. Armelin, C. Alemán, F. Estrany, J. Polym. Res. 2006, 13, 193.

[45] T. Higuchi, J. Pharm. Sci. 1963, 52, 1145.

[46] R. W. Korsmeyer, N. A. Peppas, in, Controlled Release Delivery Systems, (Eds., T. J. Roseman, S. Z. Mansdorf), Marcel Dekker, New York 1983.

[47] B. Amsdem, Macromolecules 1999, 32, 874.

[48] W. N. E. Dijk-Wolthuis, J. A. M. Hoogeboom, M. J. van Steenbergen, S. K. Y. Tsang, W. E. Hennink, Macromolecules 1997, 30, 4639.

[49] Z. Chen, L. Zhu, T. Song, J. Huang, Y. Han, Anal. Chim. Acta 2009, 635, 202. 